\title{
MILK AGGRAVATES ASTHMA - THE TRUTH OR THE PERCEPTION
}

\author{
Muhammad Khalid Azam Khan, Shazia Naz*, Abdul Latif Khattak, Nauman Kashif, Syed Karamat Hussain Shah \\ Bukhari, Asif Ullah Khan \\ Combined Military Hospital Lahore/National University of Medical Sciences (NUMS) Pakistan, *Rangers Teaching Hospital, Lahore Pakistan
}

\section{ABSTRACT}

Objective: To assess the notion that milk can cause or aggravate asthma and break this myth.

Study Design: A cross sectional study.

Place and Duration of Study: Medicine department, Combined Military Hospital Lahore, from Jan 2019 to Dec 2020.

Methodology: A survey was conducted whereby known asthmatics were questioned about their opinion weather milk aggravates their asthma. Those who confirmed their positive response were exposed to milk and some liquid resembling milk, and their Lung functions were tested after each drink. The 42 patients who considered milk as the primary aggravator were called for the study for spirometry

Results: A total of 600 people from the general population were surveyed. Two hundred and six (34.3\%) of them were illiterate, $394(65.6 \%)$ were educated from middle to graduates. In the first milk/milk encounter, the combined dyspnea scale showed increase of $50.3 \%$ and improvement of $0.008 \%$ in FEVI/FVC. In the second substitute /milk encounter, the dyspnea score showed an increase of $61.8 \%$ and an increase of $0.90 \%$ in FEVI/FVC. In the third milk/substitute encounter the dyspnea score showed a decrease of $22.9 \%$ and the FEVI/FVC decreases by $5.5 \%$. In the 4 th substitute/substitute encounter, dyspnea scores decreased by $8.4 \%$ while the pre and postencounter FEVI/ FVC scores were 2726 and 2711 with $0.55 \%$ decrease with insignificant $p$-value $>0.05$.

Conclusion: Drinking milk or milk substitute has negligible effect on the spirometric parameters.

Keywords: Dyspnea score, FEVI/FVC ratio, Milk allergy.

This is an Open Access article distributed under the terms of the Creative Commons Attribution License (http://creativecommons.org/licenses/by/4.0), which permits unrestricted use, distribution, and reproduction in any medium, provided the original work is properly cited.

\section{INTRODUCTION}

Asthma is global health issue and most common disease among children which affects all age groups with prevalence from $1 \%$ to $21 \%$ in adults and nearly $20 \%$ in children ${ }^{1}$. According to WHO estimates, a total of 339 Million people were affected worldwide with asthma in 2016 and causes around $80 \%$ asthma related deaths occur in low to middle income communities ${ }^{2,3}$.

Food allergy is a common entity and is thought to be on the risewith the incidence of up to $10 \%$ in some regions 4,5 . In the United States the incidence of food allergy is reported to be $6-8 \%$ with the incidence of milk allergy being $1.94 \%{ }^{6}$. The incidence of food allergy has been reported as $6.7 \%$ in Canada and $5.9 \%$ in European countries 7,8 . The perception that food items can trigger

Correspondence: Dr Muhammad Khalid Azam Khan, Classified Medical Specialist \& Pulmonologist, CMH Lahore Pakistan Received: 06 Jul 2020; revised received: 10 Oct 2020; accepted: 15 Oct 2020 or aggravate asthma is common. The cow's milk which is an important component of a healthy human diet can cause or aggravate asthma is widely held not only in asthmatic patients but in the general population as well 9 . The prevalence of cow's milk allergy (CMA) occurs between $0.3 \%$ and $5 \%$, relatively higher in children than adults. Drinking milk or eating dairy products doesn't cause asthma. However, if someone has a dairy allergy, it may trigger symptoms that are similar to asthma. People who are allergic to cow's milk can also be allergic to milk from other animals such as goats, sheep and buffalo ${ }^{10}$.

If someone has both asthma and dairy allergy, milk or dairy products may worsen asthma symptoms. About $40-50 \%$ of children with asthma also have some kind of dairy and other food allergies and are more susceptible to have asthma or other allergic conditions than children without food allergies. Adults are much less inflicted with milk allergy than children ${ }^{11,12}$. 
In Thailand using oral food allergy test as the yard stick, $9.1 \%$ of asthmatics and $28.6 \%$ of the patients with rhinitis were found allergic to some food component. In this group of allergic patients, cow's milk allergy was found to have the highest incidence of $31 \%{ }^{13}$. Symptoms of milk allergy differ and may range from mild reactions to a severe allergic reaction called anaphylaxis. Symptoms may occur immediately or may take some time to develop ${ }^{14,15}$.

Risk factors for developing food allergy include family history for food allergy, male gender ${ }^{16}$, ethnicity with it being more common in Asians and black races than whites vitamin D insufficiency ${ }^{16}$. It has also been associated with filgarin gene mutations and stat 6 gene polymorphism ${ }^{17,18}$.

The rationale of the study is to nullify the commonly held belief that milk is associated with aggravation of asthma and deprive the people of this nutritional drink in their diet. However it should be noted that people with known food allergy or milk intolerance should be differentiated from people who have fear of their disease aggravation without any solid evidence.

\section{METHODOLOGY}

After getting approval from the hospital ethics committee, a survey was conducted in different markets of the city and asthmatic patients reporting to the Hospital where by adults of either gender were questioned about asthma, its causative factors and probable food items aggravating asthma. Inclusion Criteria were Asthmatic patient above 12 years of age. Exclusion criteria included known chest disease other than asthma, positive chest $x$-ray, diabetics, smokers current or past, asthmatics with FEVI less than $60 \%$, recent history of asthma exacerbation, patients with signs of upper respiratory tract infection and patients with signs of respiratory distress.

Those patients who thought that milk was the primary aggravator were then called to conduct this study. After taking a written consent they graded themselves on a numerical dyspnea score marked $0-10$ with 0 being completely nor- mal and 10 being the most breathlessness ever experienced by them. A detailed present and past history was taken and patients were assessed by clinical examination and a blood sugar, $x$-ray chest and any other appropriate lab or radiological investigation were carried out as and if indicated by the history and clinical examination of the patient. A spirometric lung function study was then carried out particularly focusing on FEVI and FVC.

After 15 minutes they were given either cow's milk flavored with chocolate or cows milk substitute which was made to look and taste like chocolate milk. For this purpose Ensure powder (TM) was supplemented with chocolate and white icing color which consisted of can syp, sugar glycerol, carmosine, gelling agent agar gum, preservative, potassium sorbate, and citric agent. Both were served at room temperature in a $250 \mathrm{ml}$ transparent glass. The patient on the first occasion were given milk and they were informed that they were drinking milk. On the second occasion they were given the milk substitute and they were misinformed that they were drinking milk. A third time they were given milk and were misinformed that they were drinking a substitute. On the fourth and final encounter of the study they were given a substitute and informed correctly about the nature of the drink. On each encounter a dyspnea score on the numerical dyspnea scale was calculated 15 mins before and after the encounter. Spirometric lung function studies were also done after calculating the dyspnea scale both prior and after the encounter. The patient were kept at the lung function studies lab for one hour after the procedure and a dyspnea scale was again marked at the end of the first hour.

\section{RESULTS}

A total of 600 adults from the general population were surveyed, 456 (76\%) were males $144(24 \%)$ were females. The overall mean age was $33.4 \pm 16.3$ SD years. Two hundred and six $(34.3 \%)$ of them were illiterate, 394 (65.6\%) were educated from middle to graduates. Fifty four $(9 \%)$ gave history that they were asthmatics and 
$546(91 \%)$ thought that they had no asthma however $522(87 \%)$ knew somebody who had asthma, $533(88.3 \%)$ out of 600 people questioned

Table-I: Demographics of participants.

\begin{tabular}{l|c}
\hline Variables & n (\%) \\
\hline Age (Years) & $54(9 \%)$ \\
\hline $12-18$ & $134(22.3 \%)$ \\
$19-30$ & $168(28 \%)$ \\
$31-45$ & $152(25.3 \%)$ \\
$46-60$ & $92(15 \%)$ \\
$>60$ & $456(76 \%)$ \\
\hline Gender & $144(24 \%)$ \\
\hline Male & $206(34.3 \%)$ \\
Female & $394(65.6 \%)$ \\
\hline Education & $118(19.6 \%)$ \\
Illiterate & $92(15.3 \%)$ \\
Literate & $108(18 \%)$ \\
Middle & $76(12.6 \%)$ \\
Matriculation &
\end{tabular}

Table-II: Incidence of food allergy and asthma types.

\begin{tabular}{l|c}
\hline Variables & n (\%) \\
\hline Asthma & $54(9 \%)$ \\
Asthmatics & $546(91 \%)$ \\
No personal experience & $522(87 \%)$ \\
Know someone with Asthma & $533(88.3 \%)$ \\
\hline Asthma by Food & $67(11.1 \%)$ \\
\hline Yes & $504(84 \%)$ \\
No & $76(12.6 \%)$ \\
\hline Asthma Type & $20(3.3 \%)$ \\
\hline Allergic & \\
Heridatry & $257(48 \%)$ \\
No idea & $199(37.3 \%)$ \\
\hline Food & $77(14 \%)$ \\
\hline Milk &
\end{tabular}

were convinced that one or the other food item could aggravate or precipitate asthma and 67 $(11.1 \%)$ thought that food had no relation to asthma rather dust or other environmental agents were responsible. Two hundred and fifty seven $(48.2 \%)$ thought that milk is most important and common food item causing aggravation of asthma.

The $73 \%$ patients who thought that asthma is an allergic disease when asked about their personal experience regarding which food item aggravated their disease $42(57.5 \%)$ considered milk as the commonest agent while 26 (35\%) considered rice and $5(6 \%)$ considered bananas as the primary agent in this respect. The $42(57.5 \%)$ individuals who considered milk as the primary aggravator were called for the study after consenting to the study. They were explained about the procedure and written consent was taken. Thirty seven $(88 \%)$ of the 42 completed the study.

In the first encounter, labeled as "milk/milk" when milk was given and the patientswere told that they were drinking a glass of milk, the combined dyspnea scale before drinking was 157 while 15 minutes after the drinking the combined dyspnea score of all 37 patients was 236 which is an increase of $50.3 \%$. The combined FEVI/FVC percentages of the 37 patients added upto 2780 prior to the encounter and 2804 after the encounter which was an actual improvement of $0.008 \%$. So while the subjective dyspnea increased by $50.3 \%$, the objective FEVI/FVC also paradoxically increased by $0.008 \%$.

In the second encounter labeled as a substitute/milk" when patients were given the substitute and were misinformed that it was milk, the dyspnea score before the encounter was 144, while after the encounter was 233 which was an increase of $61.8 \%$. However, the combined FEVI/ FVC percentage before and after the procedure was 2621 and 2645 respectively, which was an

Table-III: Effect on dyspnea score and FEVI/FVC Ratio.

\begin{tabular}{l|c|c|c|c}
\hline Variables & First Encounter & Second Encounter & Third Encounter & Fourth Encounter \\
\hline Dyspnea Score Before & 157 & 144 & 148 & 153 \\
\hline Dyspnea Score After & 236 & 233 & 114 & 140 \\
\hline Difference of Dyspnea Score & 79 & 89 & -34 & -13 \\
\hline FEV1/FVC prior & 2780 & 2621 & 2690 & 2726 \\
\hline FEV1/FVC after & 2804 & 2645 & 2542 & 2711 \\
\hline Difference FEV1/FVC & 24 & 24 & -148 & -15 \\
\hline
\end{tabular}


increase of $0.90 \%$.

In the third encounter labeled as "milk/ substitute" when the patients were given milk and misinformed that it was a milk substitute the result were a pre-procedure dyspnea score of 148 and a post-procedure score of 114 which was a decrease of $22.9 \%$ and the FEVI/FVC was 2690 prior to the encounter and 2542 after the procedure showing $5.5 \%$ decrease. In this encounter there was a post procedure decrease in the dyspnea score of $22.9 \%$, while there was a decrease in the combined FEVI/FVC of $5.5 \%$.

In the 4th and final encounter labeled as "substitute/substitute" the patient was actually given a substitute and was informed correctly about the nature of the fluid the pre-encounter and post encounter dyspnea scores were 153 and 140 respectively showing $8.4 \%$. Percentage decrease while the pre and post-encounter FEVI/ FVC scores were 2726 and 2711 was $0.55 \%$.

Table-IV: Statistical analysis.

\begin{tabular}{l|c}
\hline Regression & 0.828 \\
\hline Possible Error & 43.03 \\
\hline Confidence Interval & $95 \%(0.05)$ \\
\hline$p$-value & 0.1716 \\
\hline Two Tail t-test & 1.94 \\
\hline Upper Value & -0.6 \\
Lower Value & \\
\hline
\end{tabular}

Statistical test indicates that FEVI and FVC score of milk experiment is positive. Asthema can be caused by lactose allergy. Asthma patients would have severe reaction after milk exposure. By applying t-test on 95\% confidence interval, we found insignificant $p$-value of 0.17 which was $>0.05$.

In our present study $88.3 \%$ of our general population think that one or the other food item can aggravate asthma. Amongst this group 48.2\% blamed milk while $37.3 \%$ and $14.4 \%$ respectively thought that rice and bananas are the main triggers of asthma.

\section{DISCUSSION}

A majority of our general population and asthmatic patients believe that asthma is an allergic disease and that milk is the primary food agent that aggravates asthma. However, when tested objectively drinking milk or milk substitute had negligible effect on the spirometric parameter. Nevertheless the drinking of milk or sham milk had appreciable effects on the spirometric parameters. Drinking of substitute or sham substitute milk neither affected the subjective dyspnea score. The subjective dyspnea scale nor the objective FEVI/FVC score changed significantly.

In a study by Omer et al, $67 \%$ of asthmatics thought that rice aggravated their asthma while $42 \%$ indicated milk as a trigger ${ }^{1}$. Insame study $42 \%$ of asthmatic patients were convinced that milk was their asthma trigger while $41 \%$ and $5 \%$ perceived rice and bananas respectively as main triggers of asthma. In our study $48 \%$ asthmatics attributed milk as the trigger of Asthma, and $37.3 \%$ and $14 \%$ thought of rice and banana as the trigger of disease.

However there is a difference in perception and the realty of the food allergy. According to one study the parental complaints of food hyper sensitivity in 6 years olds was $11.8 \%$ but when history along with skin prick test and open food challenge were utilized, the incidence came down to $2.5 \%$ which further reduced to $1.6 \%$, when double blind challenge was added to the diagnosis ${ }^{19}$.

The majority of the patients with milk allergy present in the first year of life. $57 \%$ of the children resolve their allergy by age $4-5$ year and the median age of outgrowing the disease is 10 years $^{20}$. Children with non IgE mediated disease develop tolerance to cows milk earlier than those with lgEmediated disease. Milk allergy accounts for about $20 \%$ of the childhood food allergies and $2.5 \%$ of the total $\operatorname{lgEand}$ non $\operatorname{lgE}$ mediated reactions. Compared to children the allergy to cows milk protein tends to persist longer in adults. Only $28 \%$ of adults are symptom free after 4 years of diagnosis ${ }^{21}$.

Interestingly in a local Pakistani study, when skin prick test was used $39.9 \%$ people were found to be sensitive to one or more component of food 
while when oral food test was used for the same purpose the incidence was $9 \%$. But none of the patients were allergic to the cow milk ${ }^{22}$.

\section{CONCLUSION}

The above results while not denying the presence of milk allergy or intolerance however disapproves the perception of milk as a common aggravator of asthma. Hence the perception of milk as a common aggravator of asthma is a myth and not a reality.

\section{CONFLICT OF INTEREST}

This study has no conflict of interest to be declared by any author.

\section{REFERENCES}

1. Irfan O, Irfan B, Khan ZA, Tahir M, Zubairi ABS, Khan JA. Knowledge about Asthma: A cross sectional survey in four major hospitals of Karachi. J Pak Med Assoc 2017; 67(11): 1787-90.

2. Hazir T, Das C, Piracha F, Waheed B, Azam M. Carers' perception of childhood asthma and its management in a selected Pakistani community. Arch Dis Child 2002; 87(4): 287-90.

3. To T, Stanojevic S, Moores G, Gershon AS, Bateman ED. Global asthma prevalence in adults: findings from the cross-sectional world health survey. BMC Public Health 2012; 12(1): 204.

4. Khan AA, Tanzil S, Jamali T, Shahid A, Naeem S, Sahito A. Burden of asthma among children in a developing megacity: childhood asthma study, Pakistan. J Asthma 2014; 51(9): 891-99.

5. Van Ree R, Ponlsen K, Wong G. Ballmer-Weber BK, Zhongshan $\mathrm{G}$, Xudong J. Food allergy definitions, prevalence, diagnosis and therapy. Chin J Prevent Med 2015; 49(1): 1-17.

6. McGowan EC, Keet CA. Prevalence of self-reported food allergies in The National Health and Nutritional examination Survey (NHANES). J Allergy Clin Immunol 2013; 132(5): 1216-19.

7. Gupta RS, Springston EE, Warrier MR, Smith B, Kumar R, Holl $\mathrm{JL}$, et al. The prevalence severity and distribution of childhood allergy in the United. Pediatr 2011; 128(1): 9-17.

8. Soller h, Ben-Shoshan M, Harrington DW, Vieille SL, Elliot SJ, Clarke AE, et al. Overall prevalence of self-reported food allergy in Canada . J Allergy Clin Immunol 2012; 130 (4): 986-88.
9. Nwarn B, Hickstein L, Panesar SS et al. The epidemiology of food allergy in Europe: A systemic review and metanalysis. Allergy 2014; 69(1): 62-75.

10. Hadley C. Food allergies on the rise? Determining the prevalence the food allergy and how quickly it is increasing,is it the first step in tackling the problem. EMBO Rep 2006; 7(11): 1080-83.

11. Lam HY, Van Hoffen E, Mchelson A, Guikers K, Vander Tas $\mathrm{CH}$, Koomen $\mathrm{CAB}$, et al. Cows milk allergy in adults is rare but severe: both casein and whey proteins are involved. Clin Exp Allergy 2008; 38(6): 995-1002.

12. Warren CM, Jhaveri S, Warrier MR, Smith B, Gupta RS. The epidemiology of milk allergy in US children. Ann Allergy Asthma Immunol 2013; 110(5): 370-74.

13. Sripramong G, Visitsunthorn K, Srisusuwatchari W, Pacharan P, Jirapongsananurnk $\mathrm{O}$, Visitsunthorn N. Food sensitization and food allergy in allergic Thai patients from a tertiary care centre in Thailand. Asian Pac J Allergy Immunol 2019;

14. Skriapak JM, Matsni EC, MuddK. The natural history of cows milk allergy. J Allergy Clin Immunol 2007; 120(5): 1172-77.

15. Santos A, Dias A, Pinheiro JA. Predictive factors for the persistence of cows milk allergy. Pediatr Allergy Immunol 2010; 21(8): 127-34.

16. Allen KJ, Koplin JJ, Posonby AL, Gurrin LC, Wake M, Vuiller$\min \mathrm{P}$, et al. Vitamin D insufficiency is associated with challenge proven food allergy in infants. J Allergy Clin Immunol 2013; 13 (4): 1109-16.

17. Tan HT, Ellis JA, Koplin JJ et al. Fillagrin loss of function mutation do not predict food allergy overand above the risk of food sensitization among infants. J Allergy Clin Immunol 2012; 130(5): 1211-13.

18. Hancock DB, Romien 1, Chin GY. Stat 6 and LRPI polymorphisms are associated with food allergens sensitization in Mexican children. J Allergy Clin Immunol 2012; 129(6): 1673-76.

19. Venter C, Perera B, Grundy J, Clayton CB, Arshad SH, Dean T. Prevalence and sensitization reported and objectively assessed food hypersensitivty amongst six year old children: A population based study. Pediatr Allergy Immunol 2006; 17(5): 356-63.

20. Elizur A, Rajwan N, Gold berg MR, Leshono M, Cohen A, Katz Y. Natural course and risk factors for persistence of $\operatorname{lgE}$ mediated cows milk allergy. J Pediatr 2012; 161 (3): 482-87.

21. Skriapak JM, Matsni EC, MuddK. The natural history of cows milk allergy. J Allergy Clin Immunol 2007; 120(5): 1172-77.

22. Inam M, Shafique RH. Roohi N, Irfan M, Abbas S, Ismail M. Prevalence of sensitization to food allergens and challenge proven food allergy in patients visiting allergy centers in Rawalpindi and Islamabad, Pakistan. Spring Plus 2016; 5(1): 1330-50. 